\title{
Conflicto armado, problemática de poderes que ha vulnerado a la sociedad colombiana*
}

\author{
Armed conflict, problems of powers has violated \\ colombian society
}

\section{Conflitos armados, problemas de poderes violou sociedade colombiana}

\author{
Luz Marina Obando Silva* \\ Yoesneth Camila Viscaya Puentes" \\ Miryam Cristina Fernández Cediel
}

Recibido 10. 10.2016 • Arbitrado 26. 02. 2016 • Aprobado 20. 04. 2016

\section{Resumen}

Este artículo presenta una revisión bibliográfica de los hitos de la historia del conflicto armado colombiano desde 1948 con la muerte de Jorge Eliécer Gaitán hasta la actualidad, exponiendo las posibles causas, secuelas y la reparación integral que se debe realizar a los afectados por este flagelo. El propósito es la conservación de la memoria his-

Este artículo es parte de los productos de una investigación de la Universidad Surcolombiana desarrollada en el 2013, titulada: "Las memorias colectivas, desde la mirada de las emociones, de los hogares que han vivido la violencia política y que como consecuencia son desplazados que ahora residen en Neiva".

** Psicóloga de la Universidad Surcolombiana, integrante del grupo de investigación Crecer. Auxiliar de investigación de "Las memorias colectivas, desde la mirada de las emociones, de los hogares que han vivido la violencia política y que como consecuencia son desplazados que ahora residen en Neiva"

*** Psicóloga de la Universidad Surcolombiana, integrante del grupo de investigación Crecer. Auxiliar de investigación de "Las memorias colectivas, desde la mirada de las emociones, de los hogares que han vivido la violencia política y que como consecuencia son desplazados que ahora residen en Neiva"

**** Psicóloga de la Universidad Surcolombiana, magister en psicología, magister en conflicto, territorio y cultura, estudiante de $\mathrm{PhD}$ en psicología, miembro del grupo de investigación Crecer, profesora asistente del programa de psicología de la Universidad Surcolombiana, Neiva, Colombia, investigadora principal, cristina.fernandez@usco.edu.co 
tórica de los colombianos, para evitar el riesgo de un olvido y promover la compresión del alcance de esta lucha insurgente que permita la no repetición. Se concluye que este fenómeno de violencia es muy complejo debido a su multicausalidad por este motivo es importante enfocarse en el análisis de las diversas perspectivas para lograr la deseada paz.

Palabras clave: Conflicto armado, causas, secuelas, reparación, proceso de paz.

\begin{abstract}
This article presents a literature review of the milestones in the history of the Colombian armed conflict since 1948 with the death of Jorge Eliécer Gaitán to the present, exposing the possible causes, sequels and integral reparation to be performed to people affected by this scourge. The purpose is to preserve the historical memory of Colombians, to avoid the risk of forgetting and promote understanding of the scope of this insurgent struggle that allows non-repetition. We conclude that this phenomenon of violence is very complex due to its multicausality, therefore, it is important to focus on the analysis of different perspectives to achieve the desired peace.
\end{abstract}

Keywords: Armed conflict, causes, consequences, repair, peace process

\title{
Resumo
}

Este artigo apresenta uma revisão da história do conflito armado colombiano desde 1948, com a morte de Jorge Eliécer Gaitán, até a atualidade, expondo as possíveis causas, sequelas e a reparação integral que se deve fazer aos afetados por este flagelo. O propósito é a conservação da memória histórica dos colombianos para evitar -se o risco do esquecimento e promover a compreensão do alcance desta luta insurgente para que não se permita a sua repetição. Conclui-se que 
este fenômeno da violência é muito complexo devido à sua multicausalidade. Por este motivo é importante enfocar em análises das diversas perspectivas para alcançar a tão desejada paz.

Palavras chave - conflito armado, causas, sequelas, reparação, processo de paz.

\section{Introducción}

Colombia es un país que ha sufrido por más de 60 años de violencia a través de su historia, en los que ha tenido como principales actores al gobierno, a las fuerzas armadas de Colombia y los grupos al margen de la ley como las guerrillas y los paramilitares, que se fortalecieron al vincularse con el narcotráfico, arriesgando la seguridad de la población civil, quienes son las principales víctimas, vulnerando el Derecho Internacional Humanitario (DIH) y los Derechos Humanos (DDHH) (Neira,1990; Sabucedo, y otros, 2014).

Este documento producto del ejercicio de la construcción contextual e histórica de la investigación "Las memorias colectivas, desde la mirada de las emociones, de los hogares que han vivido la violencia política y que como consecuencia son desplazados que ahora residen en Neiva" promovida por la Universidad Surcolombiana, compilará los hitos de la historia del conflicto armado colombiano, desde el periodo de 1948 tomando como factor detonante la muerte del líder político Jorge Eliécer Gaitán, que le dio inicio al periodo de violencia más largo que ha tenido Colombia.

En este conflicto se da la intervención de las guerrillas más representativas como las FARC, ELN, EPL y M-19, las cuales se formaron con una visión revolucionaria, pero que con el tiempo se transformó en una lucha por ganancias y el control territorial. Por otra parte, los paramilitares fue un grupo que se identificaba como defensor de la población colombiana y enemigo de las guerrillas, sin embargo, se trataba de otro grupo insurgente que desangraba a la nación. Luego de ello, aparece el narcotráfico, el tercer actor más importante de esta lucha armada, dejando huellas marcadas de sus acciones garrafales. 
Por último, se abarcan las causas que llevan a la vinculación de estos grupos armados; las secuelas que dejan los eventos violentos en la población y la reparación que debe realizar el gobierno ahora que se encuentra en medio de un proceso de paz, en el cual discuten cinco puntos fundamentales que transformen la economía, la democracia, la justicia, la eliminación del narcotráfico y así la terminación el conflicto armado.

\section{La esperanza de un pueblo oprimido}

Jorge Eliécer Gaitán nace en 1898, un líder político conocido como el "caudillo", quien estudió derecho y ciencias políticas en la Universidad Nacional de Colombia, reconocido por su interés en proteger la clase obrera, preocupado por la situación de pobreza y sometimiento por parte de los dirigentes políticos.

Uno de los hechos que llevó a su inmortalidad, fue su valentía y osadía al mostrar el horror cometido por el gobierno conservador en complicidad con la "united fruit company".

El suceso conocido comúnmente como "la masacre de las bananeras" ${ }^{\prime \prime}$ ocurrido en 1928, donde fueron asesinados más de mil trabajadores que reclamaban sus derechos.

El inconformismo por el mal manejo del gobierno conservador, impulsó a los liberales a tomarse el poder político en las elecciones presidenciales de 1930, derrotando este mandato que llevaba alrededor de 50 años, lo cual dio inicio así a la llamada "república liberal", que tuvo una duración de 16 años culminados en 1946. Este periodo estuvo mar-

1 Los trabajadores de la united fruit company, en Ciénaga Magdalena, estuvieron durante casi un mes en huelga ya que la frutera no había aceptado algunas peticiones que eran: la abolición del sistema contratista, el aumento de los salarios, el descanso dominical remunerado, la indemnización por accidente y la construcción de viviendas, resaltando que esta era la única forma de trabajo que tenían los pobladores en esta región.

Los trabajadores siguieron persistiendo pero el día 5 de diciembre de 1928 a las once de la noche, cuando se encontraban reunidos en la estación del tren, llegó el ejército a leer un decreto del gobernador del Magdalena en el que ordenaba el retiro de los huelguistas pero el desacato de estas exigencias, ocasionó los dispararos sin compasión de los soldados a las personas que sólo reclamaban sus derechos, dejando como consecuencia a más de mil masacrados, por lo tanto a este hecho se le da el nombre de "Masacre de las Bananeras". 
cado por la agudización de la violencia y la imposición de la autoridad ejercida al perseguir, desterrar y aniquilar en diferentes regiones a los conservadores (Arboleda, 2013; Perea, 2009; Trejos, 2011).

Las declaraciones de Jorge Eliécer Gaitán por este genocidio, lo convirtió en el representante de las clases sociales de bajos recursos económicos, asunto poco beneficioso para los dirigentes de los partidos políticos tradicionales (conservador y liberal); puesto que el "caudillo", aunque hacia parte del liberalismo, tenía afinidad hacia la izquier$\mathrm{da}^{2}$ y les generaba incontables críticas a través de sus osados discursos, como el realizado en mayo de 1946, en donde resaltó el vínculo corrupto entre partidos:

Los oligarcas conservadores colaboraron con todas las corrupciones de los oligarcas liberales que nosotros criticamos, se enriquecieron con el mismo dinero, hicieron los mismos contratos [...] estuvieron de acuerdo con las misma inquietudes y ahora la casta cesante de los otros oligarcas quieren tomar también su asiento para hacer dentro del partido conservador lo que los oligarcas hicieron en su puesto... con nuestro partido y en nuestro gobierno (citado por Tahar, 2009, p. 256).

Por estos motivos de disputa de poder, Gaitán renuncia al liberalismo y crea una nueva fuerza política independiente a la oligarquía, conociéndose en 1933 la unión nacional izquierdista revolucionaria (UNIR), que no tuvo el éxito esperado por la influencia de los partidos tradicionales hacia la ciudadanía, lo que convirtió en una utopía ganar las elecciones presidenciales dentro de un nuevo movimiento político.

Posteriormente en 1934 Gaitán regresó a las filas liberales, aún más crítico con los oligarcas, quienes en retaliación frenaron algunas iniciativas como la de modificar el sistema económico del país por medio de una reforma agraria; pero no impidieron que redujera su popularidad (Arboleda, 2013). El acogimiento era inigualable, las personas veían en él, al presidente del pueblo oprimido, aunque estas ilusiones se des-

2 Al decir que Gaitán tenía afinidad hacia la izquierda, se refiere a que estaba en contra de algunos ideales de los partidos tradiciones. 
vanecieron el 9 de abril de 1948, día en el cual Gaitán fue atacado por un hombre, recibiendo así varios impactos de bala que ocasionaron su muerte al momento de salir de su oficina situada en el centro de Bogotá (Jiménez, 2013). Este suceso despertó odio y furor en sus seguidores, porque en su imaginario les habían arrebatado un líder que pudo haber marcado la diferencia en el gobierno.

Tras este acontecimiento, la multitud se levantó en contra de este crimen realizado por Juan Roa Sierra, un sicario, que pagó las consecuencias de su actuación, fue atrapado y linchado a pesar de sus intentos de huir, para luego arrastrarlo por las calles de la ciudad, llegando al Palacio Presidencial donde pretendían asesinar al actual mandatario Mariano Ospina Pérez y así sosegar su ira, ya que lo consideraban culpable del asesinato de Gaitán por no brindarle la seguridad necesaria en su candidatura; sin embargo, las personas fueron retiradas por el accionar del ejército y en las puertas del palacio dejaron al homicida amarrado con dos corbatas al cuello, para exaltar el dolor que sentían (Jiménez, 2013).

Bogotá a las tres de la tarde, se encontraba vestida en llamas, la muchedumbre seguía enfurecida y las calles estaban adornadas de sangre y llanto con más de 3 mil muertos, llevados a los corredores del cementerio central y enterrados en fosas comunes para no tener problemas de salubridad pública; esta rebelión popular será recordada por los colombianos como "el bogotazo" (Tahar, 2009).

El asesinato de Gaitán marcó una nueva época denominada el periodo "la violencia" que inicio desde 1948 hasta 1965 (Ríos Sierra, Bula Escobar y Brocate Pirón, 2013) y se expandió por toda la nación caracterizándose por masacres y crímenes desgarradores realizados por los ejércitos liberales y conservadores que vulneraban los derechos de la ciudadanía. Se recuerda con gran tristeza estos años porque las víctimas eran tratadas como animales, asesinadas de forma inhumana 
mediante heridas mortales como: el corte corbata, ${ }^{3}$ bocachiquear, ${ }^{4}$ la maternidad frustrada, ${ }^{5}$ el cristo campesino ${ }^{6}$ y el corte mica ${ }^{7}$, además de realizar robos a las fincas para obtener recursos y sostener sus respectivos grupos (Jiménez, 2013). Esta forma de actuar generaba preocupación, pues demostraban su insensibilidad al matar de forma violenta a los civiles, acciones justificadas para cumplir su objetivo de transformar el Estado (Contreras, 2003).

En esta lucha civil armada, el Estado fue muy débil al no abogar por la igualdad y la garantía del DDHH y los derechos humanos vitales en disputas internas, lo que generó el despertar del pueblo al concientizarse de que estaban luchando por intereses de una minoría oligarca, como lo afirma Mabel Londoño (2012):

[...] las dos subculturas políticas existentes en el país, conformadas, a su vez, por élites políticas, se enfrentaron por el poder político, la burocracia estatal y la apropiación de tierras, arrastrando a las masas populares apasionadas que no comprendieron, sino hasta muy tarde, que los ideales de la guerra eran ajenos a sus intereses sociales (citado por Arboleda, 2013, p.56).

El rumbo político del país dio un giro, luego del caos generado en el gobierno de Mariano Ospina, la presidencia fue asumida por el conservador Laureano Gómez (1950-1952), quien tuvo una postura arbitraria frente a los liberales, pero solo estuvo dos años en el mandato por sus problemas de salud, luego fue remplazado por Roberto Urdaneta en 1952, quien continuó con sus ideales políticos, obteniendo como resul-

3 El corte corbata: consistía en hacer una incisión en el maxilar pasando la lengua, dejándola exhibida de forma macabra sobre el cuello.

4 Bocachiquear: es conocido por abrir los cuerpos para que se desangraran lentamente, esto es un término que venía de los campesinos que realizaban esta actividad con un pescado conocido como el bocachico

5 La maternidad frustrada: las mujeres que estaban próximas a tener un bebe eran asesinadas de forma inhumana, como hacerle cesárea cambiándoles el feto por un gallo.

6 El cristo campesino: una de las torturas más utilizadas para los hombres, consistía en amarrarlo con los brazos por detrás y violar en su presencia a las mujeres de la casa, además el victimario decía palabras soeces, maldiciones y amenazas, con ello trataban de humillar a la víctima para después sacrificarla, asesinándola con tiros en la cabeza o en el pecho

7 El corte mica: consistía en decapitar a la persona dejando su cabeza en las piernas o en el pecho 
tado el derrame de sangre por el estruendo de fusiles cargados de la ira imparable generada por la violencia bipartidista (Arboleda, 2013).

Debido a las actuaciones de estos presidentes, el conflicto civil armado aumentó, así que tanto los conservadores como los liberales deciden apoyar la toma del poder del general Rojas Pinilla mediante un golpe de Estado en 1953 (Pataquiva, 2009). A partir de este momento, los colombianos empezaron a confiar en que la llegada de Rojas Pinilla pacificaría la guerra, pues sentían que era la única opción para terminar esta lucha (Mesa, 2009).

Se tenía determinado que el gobierno del General duraría dos años, sin embargo, él influyó para que la asamblea constituyente extendiera su presidencia hasta 1958 (Mesa, 2009). En su mandato se resalta el incremento del desarrollo tecnológico, el reconocimiento del voto de las mujeres y la reducción del conflicto por una amnistía ofrecida a los guerrilleros, acogiendo algunos grupos del Llano, Antioquia y Santander; mientras otros siguieron su accionar en Cundinamarca, Tolima, Santander, Antioquia y Huila (Pataquiva, 2009). Pero tiempo después Rojas Pinilla mostró su faceta déspota, al oprimir los ideales de los ciudadanos opositores.

La caída de Rojas Pinilla se originó por varios eventos, el primero se da al atacar a la Corte Suprema de Justicia por liberar a un preso que había capturado antes de su presidencia. El segundo fue garrafal, exigió la muerte de unos estudiantes que se estaban manifestando en Bogotá, lo que dejó un saldo de 8 muertos y alrededor de 40 heridos y; el tercero, se ocasiona al ordenar a la prensa ${ }^{8}$ no criticar su gobierno, por lo tanto se da el cierre del diario "la unidad" y luego el periódico "el tiempo", debido a desistir de la orden del Estado (Mesa, 2009).

A parte de lo mencionado, el General crea un tercer partido político llamado Alianza Nacional Popular (ANAPO), que generó temor en los partidos tradicionales colisionándose para apartar a Rojas de la presidencia. Así que se realizó un acuerdo conocido como "el Pacto de

8 Los periodistas que no se ciñeran a las órdenes del mandatario, y escribieran, editaran, ayudaran a editar o distribuir escritos en contra del gobierno, se castigaría con cárcel de 6 meses a 2 años, ya que el presidente era el único que tenía el poder para dar sus declaraciones sobre lo que pasaba en la nación. 
Benidorm”, firmado por el liberal Alberto Lleras Camargo y el conservador Laureano Gómez. Este pacto tenía el fin de cesar la crisis política entre los dos partidos, para dar inicio al llamado Frente Nacional, en el que se turnarían la presidencia y se repartirían la administración del Estado, por lo tanto eligieron al conservador Guillermo León Valencia como candidato, pues era más probable que Rojas entregara el poder a un conservador que a un liberal (Mesa, 2009).

Sin embargo, fue muy ilusorio pensar que el dictador cedería su gobierno fácilmente, así que las elites en alianza con el comercio, la industria y los bancos, hicieron una huelga, que llevó a su renuncia el 10 de mayo de 1957. A partir de allí Rojas Pinilla entregó el poder a una junta militar, la cual tomó el mandato de la nación mientras se convocaban a elecciones (Mesa, 2009).

La gente celebraba la caída del dictador e ingenuamente pensaba que las cosas iban a mejorar, pero esos dirigentes que se unieron para terminar con la tiranía, fueron los mismos que llevaron a Rojas a la presidencia, acorralaron al país y lo rebajaron a la violencia, se unieron no con el fin de garantizar los derechos del pueblo, sino porque sus intereses personales estaban siendo afectados con el gobierno del dictador, así que como efecto no sucedió nada nuevo, seguiría la pobreza y el enfrentamiento armado.

Luego de la caída del dictador se aprobó el "frente nacional”, teniendo una duración de dieciséis años; ${ }^{9}$ los partidos pensaban que la crisis terminaría con esta nueva etapa, no obstante incumplieron las expectativas de la población colombiana, ya que la democracia se convirtió en una fantasía, las decisiones eran tomadas por las elites que impedían el acercamiento de otros movimientos como la Alianza Nacional Popular (ANAPO) y el Movimiento Revolucionario Liberal (MRL) de derecha y el Partido Comunista Colombiano (PCC) de izquierda, quienes representaban un peligro para los partidos tradicionales (Mesa, 2009).

9 Los presidentes del periodo el Frente Nacional fueron: Alberto Lleras Camargo, Liberal (1958-1962); Guillermo León, Conservador (1962-1966); Carlos Lleras Restrepo, Liberal (1966-1970); Misael Pastrana Borrero, Conservador (1970-1974) 


\section{Violencia contemporánea: una nueva era de lo mismo}

El conflicto armado en Colombia es consecuencia de un sistema político cerrado, intolerante ante la división y la formación de nuevos movimientos opositores, su objetivo es paralizar el proceso político, seleccionando dirigentes para administrar a su conveniencia. Por ello es difícil calcular las condiciones actuales en que se encuentra esta disputa y su posible resolución (Moreno, 2014; García Durán, 2008).

Un hecho evidente de esta estructura estatal es el "frente nacional" que intensificó la lucha insurgente y condujo a la creación de las guerrillas en la década de los 6o, caracterizados por buscar una revolución político-militar, entre ellas se destacan las Fuerzas Armadas Revolucionarias de Colombia (FARC), el Ejército de Liberación Nacional (ELN), el Movimiento 19 de Abril (M-19), el Ejecito Popular de Liberación (EPL), el grupo indígena Quintín Lame, el Partido Revolucionario de los Trabajadores (PRT) y la Autodefensa Obrera (ADO) (Pataquiva, 2009; Mesa, 2009; Yaffe, 2011).

Entre estas se resalta por su pie de fuerza las FARC-EP, un grupo impulsado por el Partido Comunista, fundada el 20 de julio de 1964, fecha de la primera conferencia ${ }^{10}$ en la que se denominan "bloque sur". Posteriormente en 1966 cambian su nombre a Fuerzas Armadas Re-

10 Las FARC-EP han realizado siete conferencias hasta la actualidad, cada una con un tema específico:

- La primera conferencia fue a finales de 1965 y se realizó en Marquetalia, luego del ataque del ejército. en esa conferencia se denominan "bloque sur" por encontrarse ubicado en el sur del Tolima en las confluencias del Huila, Valle y Cauca.

- La segunda conferencia se denominan FARC en 1966, se expande las guerrillas móviles por otras áreas del país.

- La tercera conferencia fue en 1969 en la región del guayabero donde se determina la formación del iv frente de las FARC en el Magdalena Medio.

- La cuarta conferencia fue en 1971 en el pato, donde se habla de un nuevo frente en el Urabá.

- la quinta conferencia se realiza en 1974 en el Meta, en la que se reorganiza el estado mayor y se impulsan normas para la financiación.

- La sexta conferencias fue en 1978 en la cual se expone el fortalecimiento de los militantes, del desdoblamiento de los frentes hasta conseguir uno en cada departamento del país.

- La séptima conferencia es realizada en 1982 en la Uribe, meta en la que se llaman ejército del pueblo FARC-EP, a la vez quieren crear una sólida organización con una estrategia política y militar dirigida hacia la toma del poder, lo que se plantea para ser un ejército con un reajusto de sus mecanismos de dirección trazando metas de crecimiento político, económico, acciones ofensivas militares y publicitarias. 
volucionarias de Colombia (FARC) y actualmente son conocidas como FARC-EP, Ejército del Pueblo (Pataquiva, 2009).

Así que las guerrillas se extendieron por el centro del país, ubicadas estratégicamente en zonas montañosas, para refugiarse de los ataques de las fuerzas armadas, su dominio se encontraba sobre los departamentos de Cundinamarca, Tolima y Meta, allí se crearon las llamadas "repúblicas independientes" conformadas por las regiones de Marquetalia, Rio Chiquito, el Alto de Sumapaz, El Duda, El Ariari, El Pato y Guayabero; denunciadas por el senador Álvaro Gómez, quien demostró que no había seguridad estatal (Trejos, 2011).

Con estas declaraciones se ejecutó un plan de acción militar en Marquetalia con el objetivo de reducir la concentración guerrillera, no obstante este ataque impulsó el fortalecimiento de estos grupos insurgentes y reivindicó sus aspiraciones sociales, políticas y económicas, como lo argumenta González (1992):

Las operaciones militares contra las "repúblicas independientes" no solo no acabaron con los brotes de insurgencia guerrillera sino que provocaron el efecto contrario: el reagrupamiento de las guerrillas y su transformación en frentes (FARC), la extensión del área de su influencia y un aumento del número de alzados en armas. [...] inauguraron la era de las guerrillas modernas, con perfiles, programas y tácticas claramente antisistema (citado por Cadena, 2008, p. 191).

El surgimientos de las guerrillas, sus constantes ataques y la presión ejercida a la nación genera la formación de los paramilitares, grupos que tenían como función brindar información a las fuerzas armadas militares y proteger los bienes de los terratenientes (militares, políticos, hacendados y campesinos) por medio de la formación de organizaciones que ofrecían seguridad privada, amparadas por la Ley 48 y el decreto 3398 de 1965. Tiempo después conformaron asociaciones como la ACDEGAM (Asociación campesina de ganaderos y agricultores del Magdalena Medio) creada en 1982 (Rivas y Rey, 2008).

Pero este no era el único fin de los paramilitares, como lo señala Velásquez (2007), sometían y asesinaban por considerar un peligro para 
la sociedad: a los campesinos, maestros y políticos, que fueran líderes de izquierda; a consumidores de sustancias psicoactivas y homosexuales, porque los consideraban unos miserables que no aportaban nada bueno a la sociedad, y para acabar con ellos en ese momento implementaron en unos sectores "toque de queda" ilícitas conocidas como "limpiezas sociales" ${ }^{12}$ de forma clandestina, debido a que el Estado afirmaba no tener conocimiento del tipo de actividades realizadas por estas organizaciones.

La violencia se había transformado en una estrategia muy despreciable de los grupos armados para infundir terror a través de masacres y asesinatos en donde los principales afectados era la población civil (Pécaut, 2013; Estrada, 2009).

Como si fuera poca la violencia que vivia Colombia, aparece un nuevo actor, el narcotráfico, una actividad ilícita que consiste en el cultivo, fabricación y distribución de drogas, surgida en los años 70 con la marihuana y en los 80 con la cocaína (Pécaut, 2001), generando grandes ganancias para sus integrantes; lo que impulsó el incremento del conflicto armado, por una disputa entre narcos con la guerrilla por el control territorial en poblaciones estrategicas. Por esta razón se crea una unión entre paramilitares y narcotráficantes, los cuales se dividian en dos principales cárteles, el de Cali dirigido por los Rodríguez Orejuela y el de Medellín bajo el dominio de Pablo Escobar (Camacho Guizado, 1991).

Pero "el problema principal no son los grupos ilegales o el mismo narcotráfico, sino el fracaso en la construcción de la nación en lo social, en lo moral y en lo político" (Márquez Quintero, 2009, p.21), que ocasionó el debilitamiento de la seguridad y la justicia del país (Echandía Castilla, 2001; Rubio, 1998).

11 El toque de queda es la prohibición, de circular libremente por las calles de una ciudad, generalmente en las horas nocturnas

12 La limpieza social se refiere a las acciones violentas que buscan amedrantar a la población, además de querer acabar con la vida de las personas "no apropiadas" para la sociedad, según el grupo criminal. 
En los años 8o, se intentó mitigar la violencia por medio de la realización del primer proceso de paz con las guerrillas de las FARC y el ELN en el mandato de Belisario Betancur (1982-1986), quien reconoció que la oposición armada es un actor político, haciendo necesario abrir diálogos y apertura democrática. A partir de esta postura se conformó el partido la "Unión Patriótica" (UP), que no tuvo el impacto esperado en algunos guerrilleros, quienes pensaban que el proceso de paz no les brindaban las garantías necesarias para llegar a un acuerdo, generando junto a la toma del Palacio de Justicia ${ }^{13}$ por parte del M-19 (1985), el cierre de las negociaciones (Pécaut, 2013; Velasquez, 2007)

En un intento de apaciguar el incremento del conflicto armado y remediar el daño causado por estos grupos, en el gobierno de Virgilio Barco (1986-1990) se resalta la derogación de la ley 48 de 1965 mediante el decreto 1194 de 1989 estableciendo penas a los colaboradores de los paramilitares (Rivas \& Rey, 2008). Además negoció con las guerrillas, el desarme y la reincorporación a la vida política legal de sus líderes, logrando su fin con el M-19, el Quintín Lame, el Partido Revolucionario de los Trabajadores (PRT), la Autodefensa Obrera (ADO) y parte del Ejército Popular de liberación (EPL), quienes se unieron a la Unión Patriótica (UP). Sin embargo, el problema surge cuando los paramilitares asesinan a más 3500 desmovilizados, borrando la esperanza de una reconciliación (Perea, 2009; Chernick, 1996).

El siguiente periodo dirigido por Cesar Gaviria (1990-1994) fue representativo por una crisis política y rebelión social generada por la muerte de los candidatos presidenciales Jaime Pardo Leal, Luis Carlos Galán, Carlos Pizarro y Bernardo Jaramillo Ossa durante el mandato anterior. Las noticias cargaban un tinte de sangre y el terrorismo fue uno de los principales componentes de impacto, no solo se estaba inseguro en la zona rural, sino también en la zona urbana.

13 La toma del palacio de justicia se realizó el miércoles 6 de noviembre de 1985 en Bogotá, este ataque se llamó la "operación Antonio Nariño por los derechos del hombre", comandada por guerrilleros del Movimiento 19 de Abril (M-19) los cuales ingresaron armados al edificio vestidos de civil seguido por la reacción de la Policía y el Ejercito, que rodearon el Palacio, iniciando con una operación de retoma que se extendió hasta el 7 de noviembre de 1985. Los hechos terminaron 27 horas después dejando un saldo de 98 muertos, entre ellos 11 magistrados y 10 desaparecidos. 
En este mandato, se quería seguir con la estrategia de su predecesor Barco, abriendo nuevamente diálogos con las FARC-EP, ELN y EPL, quienes desconfiaban de las garantías que les iban a brindar por lo sucedido con los miembros de la UP, a pesar de ello continuó el proceso que tuvo su cancelación con el secuestro del ex ministro Argelino Durán, quien murió en cautiverio a manos de EPL (Arboleda, 2013).

Además, las Fuerzas Armadas en este tiempo lograron capturar y dar de baja a algunos jefes importantes del narcotráfico, ocasionando el fin de los carteles de Medellín y de Cali, aunque la consecuencia fue inesperada ya que se fortalecieron las FARC EP, siendo los pioneros del negocio de la droga en el país (Trejos, 2013)

Cada vez la población perdía credibilidad en la política colombiana por sus antecedentes, además, por la estrecha relación entre actores insurgentes y entidades gubernamentales. Ernesto Samper (1994-1998) fue el presidente que estuvo involucrado en una ola de corrupción, pues se le acusó de tener nexos con los narcotraficantes del cartel de Cali por haber financiado su campaña, aunque no se comprobó legalmente. Asimismo, se señala que en su gobierno se expidieron las asociaciones comunitarias de vigilancia rural "Convivir", bajo la normatividad de los Decretos 2535 de 1993 y 356 de 1994; las cuales tenían como labor contribuir a las fuerzas armadas (Velásquez, 2007). Pese a ello, se resalta que en su periodo se volvió a pensar en los grupos insurgentes como actores políticos (Chernick, 1996).

A pesar de la desconfianza hacia el gobierno, los ciudadanos seguían a la espera de un Estado que terminaría el conflicto armado, ellos consideraban que era el único respaldo en contra de esta lucha, ya que con el paso del tiempo los grupos insurgentes se encontraban fortalecidos y con un mayor interés económico. Así que al finalizar el periodo de Samper llegó a la presidencia Andrés Pastrana (1998-2002), quien promovió durante su mandato las negociaciones de paz con una nueva estrategia, en la que se creó una zona de despeje militar que comprendía 42.139 km2 entre los departamentos de Meta y Caquetá, en los que se incluían las poblaciones de San Vicente del Cagúan, La Uribe, Mesetas, Vistahermosa y La Macarena. 
$\mathrm{Al}$ contrario de lo pensado, la zona se convirtió en un refugio para la guerrilla, en donde mantenían cautivos a los secuestrados, se planeaban ataques y construían laboratorios de droga (Cadena, 2008), por este motivo y la retención del avión en el que iba el Senador Eduardo Gechem se cancela el proceso de paz.

Este fallido intento dejó a Colombia devastada y a los grupos insurgentes fortalecidos, lo que permite que Pastrana tome la decisión de recibir apoyo de los Estados Unidos creándose el plan Colombia, ${ }^{14}$ en el que se reestructuraron las Fuerzas Armadas, brindando dotación para combatir a las guerrillas (Arboleda, 2013).

$\mathrm{Al}$ acabar la presidencia de Andrés Pastrana, llega Álvaro Uribe Vélez (2002-2006, 2006-2010) quien implementó la política de seguridad democrática, reduciendo el poder de los grupos insurgentes en especial las guerrillas, aunque cabe señalar que los procedimientos en los que se desarrolló esta política violaron los derechos humanos.

Uribe siendo gobernador de Antioquia en el mandato de Samper, se le acusó de impulsar la consolidación del paramilitarismo en Colombia con las reconocidas “convivir" (Velasquez, 2007); además, adoptó la Ley de Justicia y Paz que dio beneficios a los paramilitares desmovilizados (González Zapata, 2005), quienes penetraron instituciones públicas como el DAS, las Fuerzas Armadas, universidades, alcaldías, gobernaciones y el Congreso con el objetivo de controlar y participar en los proyectos del gobierno. Otro aspecto negativo en este periodo fue nublar la transparencia y credibilidad del estado, esto se puede ejemplificar con las elevadas cifras de las ejecuciones extrajudiciales atribuibles a la fuerza pública con los "falsos positivos" ${ }^{15}$ y las detenciones arbitrarias que alarmaron a la comunidad internacional (Pérez, 2011;

14 El Plan Colombia fue creado en 1999, entre los gobiernos de Clinton y Pastrana, buscaba alcanzar la paz por medio del fortalecimiento y la reorganización de las fuerzas armadas de Colombia, brindando seguridad estatal, combatiendo la guerrilla y el narcotráfico (Ríos Sierra, Bula Escobar, \& Brocate Pirón, 2013).

15 Falsos positivos: se refiere a civiles que fueron asesinados por parte de las fuerzas armadas estatales, identificándolos como integrantes de la guerrilla con el fin de mostrar resultados en el gobierno de Uribe. 
Grupo de memoria histórica, 2013). Adicionalmente, lo relacionado con el ministro de agricultura Andrés Felipe Arias, quien entregó el dinero de subsidiado para los campesinos del programa agro ingreso seguro a importantes empresarios (Pérez, 2011).

En la actualidad se encuentra el presidente Juan Manuel Santos (2010-2014 y 2014-2018), que basó su campaña en la continuación de la política de seguridad democrática de Álvaro Uribe Vélez. En este gobierno se dio paso a los diálogos de paz en el año 2012 con las FARC-EP en la ciudad de la Habana-Cuba, con el propósito de finalizar el conflicto armado que ha atormentado a Colombia por más de 60 años; proceso en el cual se discuten cinco puntos como lo refiere Arboleda (2013):

1. Innovar y realizar una activación económica en las regiones rurales que han sido afectadas por el conflicto armado, a través de la producción agrícola.

2. Garantizar la participación política y ciudadana de los futuros desmovilizados de las FARC-EP.

3. Terminar el conflicto, por medio del desarme y la reinserción de los guerrilleros, definiendo la situación jurídica a través de la justicia transicional.

4. Eliminar el negocio del narcotráfico recuperando los territorios afectados y así fortalecer el desarrollo rural.

5. Brindar a las víctimas el derecho a conocer la verdad, sobre los hechos violentos cometidos por los diversos actores.

Han pasado tres años desde que se iniciaron los diálogos de paz con las FARC - EP, proceso que ha tenido constantes críticas por no generar los resultados esperados en los tiempos acordados, ejemplo reciente fue el aplazamiento para firmar la supuesta terminación de medio siglo de guerra en Colombia, acordada para el 23 de marzo del 2016, lo que deja entrever que hay bastantes diferencias entre las partes para llegar a un acuerdo. 
Las críticas han sido mayores cada vez que el país se entera de las exigencias de este grupo armado como: la amnistía por los crímenes cometidos; la participación política y la liberación de alias 'Simón Trinidad' ${ }^{16}$ quien se encuentra privado de la libertad en E.E.U.U., para que sea el coordinador del proceso de dejación de armas. Estas situaciones ocasionaron enfrentamientos entre los sectores políticos y la inconformidad en la población civil, pues muchos colombianos consideran que se está violando los derechos humanos al no pagar cárcel los guerrilleros e incluso al darle voz en los espacios políticos.

Por otro lado, las FARC-EP consideran que el actual proceso de paz se puede cerrar, si se llega a un acuerdo sobre garantías de seguridad y la disolución del paramilitarismo. Recordemos que aunque las Autodefensas desaparecieron en el gobierno de Uribe, algunos de sus integrantes siguieron delinquiendo, ahora se conocen estos grupos como bandas criminales, llamadas BACRIM. Así que los negociadores de la guerrilla afirman que hay desarme, si desaparecen estas estructuras que han estado aliadas con sectores políticos para promover la guerra (Agencia EFE, 2016).

Esto lleva a otra duda, ¿̇se puede hablar de paz solo si se hace un acuerdo con las FARC?, porque no hay que negar que el proceso de negociación con ellos es un gran avance por ser el grupo más antiguo y con más poder; además, el gobierno afirmó que en mayo del 2016 se iniciará una negociación con el ELN (grupo que aceptó, pero no ha demostrado su interés, ya que sigue secuestrando) (Redacción Política, 2016). Sin embargo, siguen rondando dificultades que deben ser atendidas cuando se habla de paz como, por ejemplo, las BACRIM que tienen gran influencia en los departamentos del Caribe y Pacífico, y por otra parte, la corrupción en las distintas instancias del gobierno nacional, pues en parte, los dirigentes que son elegidos para que representen

16 'Simón Trinidad', así se hace conoce Juvenal Ovidio Ricardo Palmera en las FARC-EP, quien terminó haciendo parte de este grupo en el año de 1987, escaló dentro de la jerarquía de la guerrilla hasta ser jefe del Bloque Caribe y fue uno de los líderes guerrilleros que hicieron parte del frustrado proceso de diálogos de San Vicente del Caguán, durante el gobierno de Andrés Pastrana. En enero de 2004 fue capturado en Quito y condenado por el gobierno estadounidense a 60 años de cárcel por el secuestro de tres contratistas norteamericanos. 
a la población colombiana y cuiden por los derechos y deberes consagrados en la Constitución Nacional, poco defensa hacen de lo público, la protección de la sociedad y cuidado del recurso medioambiental, social y económico.

Con lo argumentado se concluye que el conflicto no se termina con la derrota militar, se requiere la protección a la población civil, que se re-establezca la democracia, el respeto por la justicia, los derechos humanos y la construcción de una sociedad equitativa por parte del Estado y la sociedad.

\section{Posibles causas y secuelas que deja el horror del conflicto armado co- lombiano}

La guerra que existe en Colombia se entiende como una crisis en el desarrollo humano, en la cual sus participantes desean una transformación social para sus fines colectivos, pero al contrario de lo pensado manipulan y someten al país, por los intereses de una minoría (Programa de las Naciones Unidas para el desarrollo, 2003; Samudio Díaz, 2006).

Freud en su escrito "De guerra y muerte" (1915, citado por Amador, 2010) refiere que cuando el individuo se ve desencantado por la unidad inestable, renuncia a las cosas que le limita la cultura, el sistema y la educación, ejerciendo la violencia. Entonces, el sujeto juega un papel importante, porque cada uno manifiesta una percepción diferente de un mismo objeto, dándole un valor particular, lo que produce un enfrentamiento entre ideales, los cuales conducen a la violencia si no se controlan. En estos diferentes puntos de vista influyen los escenarios de socialización, ya que se forma la comprensión de sí mismo (Riaño Barrera, 2006).

El concepto del actor es subjetivo, debido a que en su construcción se responde al ser y al estar en el mundo, consolidada por la intervención del ambiente y de las personas que comparten no solo espacios y tiempos, sino actividades, pasiones, pensamientos que se entrelazan y llevan o imponen una nueva forma de vida (Otero, 2006; Amador, 
2010). Por consiguiente, el sujeto en la guerra actúa en una "magicalización" ${ }^{17}$ de la conciencia, que lo lleva a caer en un estado de "embobamiento" colectivo (Barrero Cuellar, 2014).

Los motivos para ingresar a la lucha insurgente son diversos, entre los cuales se encuentran: el resentimiento, la codicia, la pobreza, la ilusión de una mejor vida, la identidad, la cultura, las creencias, los derechos y la defensa de intereses (Yaffe, 2011; Moreno, 2014; Estrada, 2009), que no sólo deja afectaciones físicas sino psicológicas debido a la reducción del otro como objeto por el deseo y el poder (Valencia y Daza, 2013). Además de esto, interviene la formación militar enseñada por los líderes de los grupos insurgentes, ligada al vínculo de amistad y apego por las experiencias vividas con sus compañeros de combate que permite la continuación de la vida delictiva (Riaño Barrera, 2006; Camacho Guizado, 1991; Amador, 2010).

Gran parte de la población que ingresa a la guerra por la vía ilegal son niños, niñas y adolescentes (NNA), vinculados por alguna de las siguientes formas según Romero Picón y Chávez Plazas (2008):

1. Voluntaria: Por fascinación a la milicia, las armas, el poder, el maltrato intrafamiliar, curiosidad o deseos de vengar la muerte de un ser querido. Sin embargo se duda de ser "voluntaria", ya que los NNA, no cuentan con un entorno adecuado, que les brinde las oportunidades necesarias para otra forma de vida.

2. Forzada: Debido a las amenazas y reclutamiento por parte de los grupos insurgentes.

3. De nacimiento: Por ser hijos de guerrilleros son considerados propiedad de esta organización.

17 Edgar Barrero Cuellar es un psicólogo social, que argumenta la guerra psicológica como una operación en la que participan elementos políticos, ideológicos, militares y religiosos, que acciona sobre cinco puntos, el físico, mental, inconsciente, mágico y espiritual.

El físico, corresponde a la vulneración del cuerpo; el mental, inhibe la capacidad intelectual y crítica de las personas; el inconsciente, neutraliza acciones injustificables (como las intervenciones imperiales en países extranjeros); el mágico, con una estrategia basada en la "magicalización" de la conciencia lleva a la gente a un estado de "embobamiento" colectivo para dejar en otros su voluntad; y el espiritual, incluye elementos de manipulación espiritual del pueblo. 
A pesar de estudiar las consecuencias que deja el conflicto armado, no se alcanza a visualizar el daño causado a los ciudadanos, pues deja huellas que conducen al trauma (Wilches, 2010). De allí la importancia de brindar una atención integral, para que las víctimas se reincorporen adecuadamente a la sociedad.

Para las víctimas lo más difícil de afrontar no es el miedo caracterizado por el acontecimiento amenazante, sino aprender a vivir en medio de la guerra, amoldarse a la situación, aunque la estrategia psicológica del conflicto armado se basa en conducir a la persona a experiencias imborrables, y así quedar sumida en las afectaciones corporales y de su entorno (Aguilera, 2003), teniendo como resultado en las víctimas: crisis emocional, ansiedad, depresión, conductas autodestructivas, irritabilidad, llanto, deseos de cambiar su identidad, perdida de vínculos familiares, inseguridad y la incapacidad para lograr sus deseos, dejando los mecanismos de defensa tales como la evasión, regresión, agresión, el olvido, la conversión reactiva y la negación (Andrade Salazar, Angarita, Perico Restrepo, Henao, y Zuluaga, 2011). Un ejemplo de ello es la "amnesia de los recuerdos traumáticos", utilizado como defensa para no recordar el hecho doloroso (Wilches, 2010).

Según Aguilera (2003) otras estrategias psicológicas que utiliza el conflicto armado para someter a las víctimas son:

- La culpa: la víctima se siente responsable de las amenazas hechas por los victimarios, causando arrepentimiento de sus acciones y perturbación.

- La tortura: es la forma más efectiva de sometimiento en el conflicto armado hacia las víctimas, provoca un estado de pánico, zozobra y terror, que afecta el equilibrio emocional.

- La desaparición forzada: lleva a una incompleta elaboración del duelo por parte de la familia y conocidos del retenido, ya que es fundamental la presencia de un cuerpo para aceptar su fallecimiento.

El secuestro ${ }^{18}$ : divide la vida de una persona al estar en cautiverio,

18 El secuestro, según Marta Lucia Aristizábal (2000) tiene cinco fases, cada una es un momento de los acontecimientos, las fases se viven individualmente, solo cuando salva la víctima se viven en grupo 
pues debe adaptarse a su nuevo entorno y al ser liberado, presenta, junto a sus allegados, tensión permanente, por el miedo a que el hecho vuelva a suceder.

Las secuelas emocionales llevan a la persona a vivir en el pasado, afectando su proyecto de vida, que impide construir motivaciones, lazos de aprobación y sentido de pertenencia. Algunas personas pueden tener sentimientos de odio por sus victimarios, que causaron determinada situación desastrosa en sus vidas, en cambio hay otros que, además del desprecio, sienten deseos de venganza que lleva a la persona a una reducción de su humanización, un recurso esencial que utiliza la contrainsurgencia como estrategia central, ejerciéndose la acción sin culpa, con indiferencia o con complacencia, generando la mitigación de la ira por medio de la violencia (Martín-Baró, 2000).

\section{La búsqueda de reparación en las víctimas y victimarios del conflicto armado}

Los hechos violentos afectan a la sociedad y quiebran el tejido social, de ahí la importancia de lograr la reparación individual, familiar y social. Sin embargo, no hay un panorama alentador, ya que estamos rodeados de injusticias que favorecen la guerra y, a la vez, niegan su presencia.

Un ejemplo es el desplazamiento forzado, que deja como consecuencia personas desamparadas por el Estado, debido a su incapacidad para garantizar los Derechos Humanos y el Derecho Internacional Humanitario, generando una desestabilización emocional en las víctimas porque no hay un reconocimiento como ciudadanos (Rodríguez, De la Torre, y Miranda, 2002; Gómez García, 2009), hecho evidenciado en las siguientes estadísticas: la Consultoría para los Derechos Humanos y el Desplazamiento (Codhes) estima que en el periodo de 1985-1995

\footnotetext{
Fase 1: Crisis inicial, momento de la captura y la noticia

Fase 2: Cautiverio, la etapa de adaptación y el proceso de negociación

Fase 3: Liberación o desenlace

Fase 4: Reencuentro familiar, adaptación y ajuste

Fase 5: Superación del trauma, se presenta cambios emocionales, laborales, afectivos.
} 
hubo un registro de 819.510; entre 1985 y 2012 cada hora fueron desplazadas 26 personas; y el Registro Único de Víctimas (RUV) reportó 4 744046 hasta el 31 de marzo del 2013, cifras que dejan a Colombia en el primer puesto a nivel mundial al tener la mayor cantidad de desplazados internos (Grupo de Memoria Historica, 2013).

Ellos conforman una nueva categoría de ciudadanos, pues el Estado no les ha brindado garantías para proteger sus derechos fundamentales, por lo tanto, se les considera subciudadanos sociales, políticos y civiles, ya que hay perdida de la vida en comunidad, rompiendo su estructura social; carecen en la satisfacción de sus necesidades básicas, son marginados en la ciudad; son vulnerables por la pérdida de libertad, por no poder regresar a sus tierras, además de una baja participación política (Gómez García, 2009).

Por lo tanto, es fundamental que se dé una atención integral a los desplazados, siendo este un deber del Estado y la sociedad, pues tienen derecho a no ser discriminados, a acceder a soluciones definitivas a su situación, a la libertad de movimiento, la convivencia, la equidad y la justicia.

La reparación según Estrada Mesa; Ripoll Núñez \& Rodríguez Charry (2010) es:

Dinamizar la configuración de identidad mediante la construcción de historias con mejores formas (Sluzki 2006), que inciden en el posicionamiento como ciudadano, miembro de una comunidad y una familia, en un momento histórico que dispone los recursos de afrontamiento con los cuales víctimas y familias han lidiado con el sufrimiento, las maneras en que se han resistido y han construido sentidos de la experiencia (p.109).

En el Programa de Atención Psicosocial y salud integral a víctimas (PAPSIVI) se brinda una reparación integral, realizándose un conjunto de actividades, procedimientos e intervenciones desarrolladas a nivel individual y colectivo, que tienen el propósito de ayudar a superar los hechos traumáticos en Colombia (Decreto 4800, 2011, Artículo 164) y 
evitar que la víctima vuelva a vivir en el terror y la impunidad, participando de manera activa en su proceso jurídico para reducir el impacto de las emociones (Rebolledo y Rondón, 2010).

Cabe resaltar que es un proceso dispendioso, aunque algunos sujetos realizan su recuperación en menor tiempo gracias a su capacidad de resiliencia, a un entorno favorable y a un acompañamiento de familiares y amigos (Wilches, 2010). A la vez es distinto en cada región de Colombia debido a su diversidad cultural y de pensamiento (Martínez Miranda, 2007; Márquez Quintero, 2009; Estrada Mesa, Ripoll Núñez, y Rodríguez Charry, 2010).

Para fortalecer el acompañamiento psicosocial en el proceso de reparación, algunas recomendaciones que refiere Rebolledo y Rondón (2010) son las siguientes:

- Aliviar el sufrimiento humano, mitigando los efectos de la violencia en el desarrollo y capacidad humana;

- Brindar protección a aquellos especialmente vulnerables a los impactos del conflicto y;

- Promover la recuperación y la reconciliación comunitaria, reduciendo el conflicto con la garantía de no repetición de los hechos, así como desarrollo social.

Una alternativa para la reparación de víctimas y victimarios es la justicia transicional, ${ }^{19}$ un mecanismo que utilizaron otras naciones que han vivido el caos político y social, alcanzando la restauración del orden. Sin embargo, para llegar a una nueva etapa se debe hacer el proceso con todos los actores armados y así evitar la misma situación dada con la desmovilización de los paramilitares en el 2006, puesto que si se acogieran todos los actores, se podría eliminar los factores que llevaron al conflicto y así obtener la reconstrucción social (Díaz Colorado, 2008).

19 La justicia transicional es una respuesta a las violaciones sistemáticas o generalizadas a los derechos humanos, la función es reconocer a las víctimas y promover iniciativas de paz, reconciliación y democracia. La justicia transicional es una justicia adaptada a sociedades que se transforman a sí mismas después de un período de violación generalizada de los derechos humanos 
Además, en la justicia transicional se tiene en cuenta el derecho a la verdad y la justicia, fundamental para la superación del hecho traumático, relevante en la reparación de la víctima y su familia (Barbosa Delgado, 2013), aunque es complejo porque depende de la disposición de los actores desmovilizados para confesar los actos de violación de los derechos humanos (González Chavarría, 2010), pues como lo afirma Martínez Miranda (2007) "no existe modo de conocer la verdad si la búsqueda de la misma no parte de las personas y comunidades que han sido afectadas directamente por el conflicto armado" (p.431).

Luego del proceso de justicia transicional, en el que se da una transformación de un estado de guerra a uno de paz; se considera importante realizar una política pública para la paz, teniendo en cuenta la integración de las experiencias traumáticas; la recuperación del papel social de las víctimas y comunidades afectadas; la reconstrucción de los proyectos vitales; la reparación de lazos y vivencias entre las personas violentadas (Aguilera, 2003; Arévalo, 2010).

Finalmente, el conflicto armado en Colombia es un tema controversial, el Estado no cumple en su totalidad las medidas tomadas para la reparación, debido al olvido de la afectación emocional que dejan en las víctimas las acciones violentas; por eso no se mide con cifras, pues se debe buscar un fortalecimiento psicológico, físico y social para que haya una reparación y reconciliación entre las víctimas y victimarios, construyendo un nuevo camino hacia la paz. Como lo argumenta Serje (2006, citado por Wilches, 2010), “de todas maneras los principales efectos de la violencia no pueden ser medidos en términos cuantitativos. La violencia cierra la posibilidad de proyectar futuros y de imaginar otras formas de convivencia, pues la vida queda atrapada por el miedo" (p.88).

\section{A manera de reflexiones finales}

- La compilación de los hitos del conflicto armado promueve que los colombianos comprendan el alcance de este y conserven su memoria histórica para evitar los riesgos de un olvido, que permita la no repetición (Velázquez, y otros, 2008). 
- El conflicto armado en Colombia ha estado presente hace 60 años, por múltiples causas en las que se resalta la inequidad, la pobreza, la precariedad política y la ausencia del Estado en las poblaciones, llevando a la formación de grupos insurgentes.

- "El frente nacional" fue un sistema político excluyente, el cual limitó su democracia a la participación de los partidos liberales y conservadores, generando inconformismo entre sus opositores y que tuvo como consecuencia la consolidación de las guerrillas.

- Los paramilitares fueron creados por el Estado con la finalidad de mitigar el conflicto armado; sin embargo, sus fines fueron más lejos de lo esperado convirtiéndose en un grupo ilegal que sometía y asesinaba sin escrúpulos.

- A pesar de las condiciones actuales y el panorama desalentador, hay que seguir pensando y analizando las posibles soluciones que puedan llevarnos a la culminación del conflicto armado, que tengan como puntos principales la protección de la población civil, el respeto por la justicia, la restructuración de la democracia, el cumplimiento de derechos y la construcción de una sociedad equitativa.

- Fomentar la educación en los afectados por el conflicto armado, eliminando la desinformación y así generar la autonomía los ciudadanos para exigir y garantizar sus derechos (Einstein y Sigmund , 2001).

- El Estado no es el causante del conflicto armado, pero si podría realizar una intervención mayor que afecte de forma positiva el panorama del país colombiano, cambiando los escenarios frágiles de una sociedad que necesita de justicia social, para lograr conservar la independencia, autonomía y equidad, retomando la confianza perdida en ellos.

- Los actores del conflicto armado demonizan a sus adversarios y los responsabilizan de los actos crueles de la lucha de intereses, contribuyendo a la deshumanización para así poder asesinar (Estrada, 2009). 
- El conflicto armado cuenta con estrategias tales como la culpa, la tortura, la desaparición forzada y el secuestro, para someter a las víctimas, llevándolas a experiencias imborrables, y así quedar sumidas en las afectaciones corporales y de su entorno.

- La reparación de las víctimas y victimarios se debe realizar de forma integral, pues el Estado ha olvidado que la recuperación del evento traumático no solo se da con el aporte económico, de necesidades básicas y materiales sino que además debe vincular lo físico, psicológico y social.

\section{Referencias}

Aguilera, A. (2003). Las secuelas emocionales del conflicto armado para una política pública de paz. Convergencia. Revista de Ciencias Sociales, 1O(31). Recuperado de http://www.redalyc.org/articulo.oa?id=10503102

Amador, J. (2010). El intersticio de la víctima-victimario: un análisis de los procesos de subjetivación en cuatro desmovilizados de grupos armados en Colombia. Universitas Humanística, (69), 163-184. Recuperado de http://www.redalyc. org/articulo.oa?id=79118943009

Andrade Salazar, J., Angarita, L., Perico Restrepo, L., Henao, N. R., \& Zuluaga, Y. E. (2011). Desplazamiento forzado y conflicto armado. Niños y niñas vulnerados en sus derechos humanos. Orbis. Revista Científica de Ciencias Humanas, vol. 7, núm. 20, pp. 51-78. Recuperado de http://www.redalyc.org/articulo. oa?id=70922149003

Arboleda, P. (2013). La violencia política en Colombia: Justicia transicional en el marco del proceso de paz entre el gobierno de Santos Y las FARC-EP. Porlegómenos. Derechos y Valores, XVI(32), pp.49-68. Recuperado de http://www.sci.unal.edu.co/scielo.php?script=sci_arttext\&pid=S0121-182X2013000200004\&lng=pt\&nrm=iso 
Arévalo, L. (2010). Atención y reparación psicosocial en contextos de violencia sociopolítica: una mirada reflexiva. Revista de Estudios Sociales, (36), pp. 2939. Recuperado de http://www.redalyc.org/articulo.oa?id=81514696003

Barbosa Delgado, F. (2013). La memoria, la historia y el derecho a la verdad en la Justicia Transicional en Colombia: Una paradoja irresoluble en el conflicto colombiano. Revista Derecho del Estado, (31), pp.97-117. Recuperado de http:// www.redalyc.org/pdf/3376/337630243003.pdf

Barrero Cuellar, E. (2014). Psicología social del autoritorismo. Apuntes para una prehistoria del conflicto armado colombiano. Tesis Psicológica, (3), pp.86-97. Recuperado de http://www.redalyc.org/pdf/1390/139012667009.pdf Cadena, J. (2008). Geografía, Conflicto y Poder en Colombia. Revista de Relaciones Internacionales, Estrategia y Seguridad, 3(2), pp.179-227. Recuperado de http://www.redalyc.org/articulo.oa?id=92712967010

Camacho Guizado, A. (1991). El ayer y el hoy de la violencia en Colombia: Continuidades y discontinuidades. En análisis político, (12), pp.23-34. Recuperado de http://www.banrepcultural.org/sites/default/files/lablaa/revistas/analisispolitico/ap12.pdf

Chernick, M. (1996). Aprender del pasado: Breve historia de los procesos de paz en Colombia (1982-1996). Colombia Internacional, (36), pp.4-8. Recuperado de http://colombiainternacional.uniandes.edu.co/view.php/241/view.php

Contreras, M. H. (2003). El conflicto armado en Colombia. Revista de derecho, (19), pp.119-125. Recuperado de http://rcientificas.uninorte.edu.co/index.php/derecho/article/view/2960/2038

Diaz Colorado, F. (2008). La justicia transicional y la justicia restaurativa frente a las necesidades de las víctimas. Umbral científico, (12), pp.117-130. Recuperado de http://www.academia.edu/5441874/La_justicia_transicional_y_la_justicia_restaurativa_frente_a_las_necesidades_de_las_v\%C3\%ADctimas 
Echandía Castilla, C. (2001). La violencia en el conflicto armado durante los años 90. Revista Opera, 1(1), pp.229-245. Recuperado de http://www.redalyc.org/articulo.oa?id $=67510112$

Einstein, A., y Sigmund , F. (2001). ¿Por que la guerra? Barcelona: Minúscula. Recuperado de https://resistencia-colombia.org/pdf/Correspondencia_Sigmund_FREUD_Albert_EINSTEIN.pdf

En mayo será primera mesa de negociación con el ELN (7 de abril de 2016). El Espectador. Recuperado de http://www.elespectador.com/noticias/paz/mayo-se-inicia-primera-mesa-publica-de-negociaciones-de-articulo-625997

Estrada Mesa, A. M., Ripoll Nuñez, K., y Rodríguez Charry, D. (2010). Intervención psicosocial con fines de reparación con víctimasy sus familias afectadas por el conflicto armado interno en Colombia: equipos psicosociales en contextos jurídicos. Revista de estudios sociales, (36), pp.103-112. Recuperado de http:// www.redalyc.org/articulo.oa?id=81514696010

Estrada, F. (2009). Evolución estratégica del conflicto armado en Colombia. Análisis político, (67), pp.156-181. Recuperado de http://www.scielo.org.co/pdf/ anpol/v22n67/v22n67ao8.pdf

Farc esperan cerrar acuerdo sobre paramilitarismo (8 de abril de 2016). El Espectador. Recuperado de http://www.elespectador.com/noticias/paz/farc-esperan-cerrar-acuerdo-sobre-paramilitarismo-ciclo-articulo-626022

García Durán, M. (2008). El conflicto armado colombiano: ¿el fin del fin? Bogotá:

Centro de investigación y educación popular. Recuperado de http://www. alboan.org/docs/articulos/canales/alboan/InformeCINEPsitu.pdf

Gómez García, L. S. (2009). Desplazados forzados en Colombia: ¿una nueva categoría de subciudadanos? Revista Opera, (9), pp.135-152. Recuperado de http:// www.redalyc.org/pdf/675/67515007009.pdf 
González Chavarría , A. (2010). Justicia transicional y reparación a las víctimas en Colombia. Revista Mexicana de Sociología, 72(4), pp.629-658. Recuperado de http://www.scielo.org.mx/scielo.php?script=sci_arttext\&pi$\mathrm{d}=\mathrm{S} 0188-25032010000400005$

González Zapata, J. (2005). Verdad, justicia y reparación en la mitología penal.A propósito de la ley 975 de 2005. Estudios políticos, (27), pp.45-63. Recuperado de http://www.redalyc.org/articulo.oa?id=16429055004

Grupo de Memoria Histórica. (2013). iBasta ya! Colombia: Memorias de guerra y dignidad. Bogotá: Imprenta nacional.

Jiménez, A. (2013). El periodo de la Violencia en Colombia y el uso de la imágenes del terror 1948-1965. Revista de Antropología Experimental, (13), pp.151-165. Recuperado de http://revistaselectronicas.ujaen.es/index.php/rae/article/ view $/ 1822 / 1578$

Marquez Quintero, M. (2009). Enseñanza de la historia del conflicto armado en Colombia: Fundamentos para la construcción de propuestas para su enseñanza en el ámbito universitario. Colombia latinoamericana de estudios educativos, 5(2), pp.205-230. Recuperado de http://www.redalyc.org/articulo. oa?id=134116861009

Martín-Baró, I. (2000). Guerra y Salud Mental. En I. Martín-Baró, Psicología Social de la Guerra: Trauma y Terapia, pp.123-141. San Salvador: UCA editores. Recuperado de http://portales.puj.edu.co/martinbaro/html_m1_a_m5/modulo_3/unidad\%202/material/Psico\%20Social\%2ode\%2ola\%20Guerra\%202.pdf

Martínez Miranda, L. G. (2007). Reparaciones desde el conflicto armado interno colombiano. En C. Mosquera Rosero - Labbé, y L. C. Barcelos, Afro-reparaciones: Memorias de la exclvitud y justicia reparativa para negros, afrocolombianos y raizales, pp.423-442. Bogotá: Universidad Nacional de Colombia- Observatorio del Caribe Colombiano. Recuperado de http://www.bdigital. unal.edu.co/1237/16/15CAPI14.pdf 
Mesa, E. (2009). El Frente Nacional y su naturaleza antidemocratica . Revista Facultad de Derecho y Ciencias Politicas , 39(110), pp.157-184. Recuperado de https://revistas.upb.edu.co/index.php/derecho/article/viewFile/283/238

Moreno, H. A. (2014). La paz imperfecta en el marco del conflicto armado en Colombia. Entramado, 1O(1), pp.202-218. Recuperado de http://www.redalyc.org/ pdf/2654/265431574013.pdf

Neira , E. (1990). Un caso intrincado de violencia:Colombia. Nueva sociedad, 141-152.

Otero, S. (2006). Emociones y movimientos sociales: algunas claves útiles para estudiar el conflicto armado. Colombia Internacional, (63), pp.174-187. Recuperado de http://www.redalyc.org/articulo.oa?id=81206309

Pataquiva, G. N. (2009). Las FARC, su origen y evolución. INISCI. Discussion Papers, (19), pp.154-184. Recuperado de http://revistas.ucm.es/index.php/UNIS/article/view/UNISo909130154A/27502

Pécaut, D. (2001). La tragedia colombiana: guerra, violencia, tráfico de droga. Revista Sociedad y Economía , (1), pp.133-148. Recuperado de http://www.redalyc. org/pdf/996/99617827006.pdf

Pécaut, D. (2013). La experiencia de la violencia: los desafios del relato y la memoria. Co-herencia, 1O(19), pp.305-311. Recuperado de http://www.redalyc.org/articulo.oa?id=77429184012

Perea, C. M. (2009). Colonización en armas y narcotráfico. La violencia en Colombia durante el siglo XX. Araucaria, 11(22), pp.99-124. Recuperado de http:// www.redalyc.org/articulo.oa?id=28211598006

Pérez, T. H. (2011). Colombia entre la paz y la guerra: una lectura a partir de la Seguridad Demócratica. Revista VIA IURIS, (10), pp.83-100. Recuperado de http://www.redalyc.org/articulo.oa?id=273919435005

Programa de las Naciones Unidas para el desarrollo. (2003). El conflicto, callejón con salida. Bogotá: UNDP.

Rebolledo, O., y Rondón, L. (2010). Reflexiones y aproximaciones al trabajo psicosocial con víctimas individuales y colectivas en el marco del proceso de repara- 
ción. Revista de estudios sociales, (36), pp.40-50. Recuperado de http://res. uniandes.edu.co/view.php/648/index.php?id=648

Riaño Barrera, E. (2006). Socialización y carreras morales en jóvenes desvinculados del conflicto armado. Tesis Psicológica, (1), pp.41-51. Recuperado de http:// www.redalyc.org/articulo.oa?id=139012673006

Ríos Sierra, J., Bula Escobar, G., \& Brocate Pirón, R. (2013). Estado, Estado de Derecho y violencia armada en Colombia (2000-2011). Revista de Paz y Conflictos, (6), pp.6-31. Recuperado de http://revistaseug.ugr.es/index.php/revpaz/article/view/427/469

Rivas, P., y Rey, P. (2008). Las autodefensas y el paramilitarismo en Colombia. CONfines de Relaciones Internacionales y Ciencias Políticas, 4(7), pp.43-52. Recuperado de http://www.redalyc.org/articulo.oa?id=63340703

Rodríguez, J., De la Torre, A., y Miranda, C. (2002). La salud mental en situaciones de conflicto armado. Biomédica, 22, pp.337-346. Recuperado de http://www. redalyc.org/articulo.oa?id=84309603

Romero Picón, Y., y Chávez Plazas, Y. (2008). El juego de la guerra, niños, niñas y adolescentes en el conflicto armado en Colombia. Tabula Rasa, (8), pp.197210. Recuperado de http://www.revistatabularasa.org/numero-8/romero.pdf

Rubio, M. (1998). La economía en una sociedad violenta. Revista de estudios sociales, (1), pp.22-32. Recuperado de http://www.redalyc.org/articulo. oa?id $=81511376004$

Sabucedo, J. M., Barreto , I., Borja, H., Lopéz Lopéz, W., Blanco, A., De la Corte, L., et al. (2004). Deslegitimación del adversario y violencia política el caso de las FARC y las AUC en Colombia. Acta Colombiana de Psicología, 69-85.

Samudio Díaz, J. (2006). Los Sujetos del Conflicto Armado Interno en Colombia. Una aproximación psicológica. Tesis Psicológica, (1), pp.27-39. Recuperado de http://www.redalyc.org/pdf/1390/139012673005.pdf 
Tahar, M. (2009). La presencia de una ausencia: Joege Eliécer Gaitán y las desventuras del populismo. Araucaria, Revista Iberoamericana de Filosofía, Política y Humanidades, 11(22), pp.251-262. Recuperado de http://www.redalyc.org/articulo. oa?id=28211598011

Trejos, L. F. (2011). Colombia y los Estados Unidos en los inicios de la Guerra Fria (1950-1966) "Raíces históricas del conflicto armado colombiano”. Memorias. Revista Digital de Historia y Arqueología desde el Caribe, 8(15), pp.47-74. Recuperado de http://www.redalyc.org/articulo.oa?id=85522637004

Trejos, L. F. (2013). Colombia: una revisión teórica de su conflicto armado. Revista Enfoques: Ciencia política y Administración pública, XI(18), pp.55-75. Recuperado de http://www.ucentral.cl/prontus_ucentral2012/site/artic/20140102/asocfile/20140102010406/enfoques18_03_luistrejos.pdf

Valencia, O. L., \& Daza, M. F. (2013). Vinculación a los grupos armados: un resultado del conflicto armado en Colombia . Diversitas, 6(2), pp.439-439. Recuperado de http://www.usta.edu.co/otraspaginas/diversitas/doc_pdf/diversitas_10/ vol.6no.2/articulo_14.pdf

Velasquez, E. (2007). Historia del paramilitarismo en Colombia. Historia (Sao Paolo), 26(1), pp.134-153. Recuperado de http://www.redalyc.org/articulo. oa?id=221014794012

Velázquez , J. F., Jaramillo Panesso, J., García, C., Gallo, H., Ramíirez, M., Villa Machado, J., y otros. (2008). Conflicto armado: memoria, trauma y subjetividad. Medellín: La carreta Editores E.U.

Wilches, I. (2010). Lo que hemos aprendido sobre la atención a mujeres víctimas de violencia sexual en el conflicto armado colombiano. Revista de estudios sociales, (36), pp.86-94. Recuperado de http://res.uniandes.edu.co/view.php/652/ index.php?id=652

Yaffe, L. (2011). Conflicto armado en Colombia: análisis de las causas económicas, sociales e institucionales de la oposición violenta. Revista en ciencias sociales, 
Conflicto armado, problemática de poderes que ha vulnerado a la sociedad colombiana

(8), pp.191-208. Recuperado de http://scholarlyrepository.miami.edu/cgi/ viewcontent.cgi ?article $=1757 \&$ context $=$ oa_dissertations 